\title{
Multiple Sclerosis, COVID-19 and Vaccines: Making the Point
}

\author{
Simona Toscano · Clara G. Chisari · Francesco Patti
}

Received: August 19, 2021 / Accepted: September 22, 2021 / Published online: October 8, 2021

(c) The Author(s) 2021

\begin{abstract}
On 11 March 2020, the World Health Organization declared the coronavirus disease 19 (COVID-19) outbreak a pandemic. In this context, several studies and clinical trials have been conducted since then, and many are currently ongoing, leading to the development of several COVID-19 vaccines with different mechanisms of action. People affected by multiple sclerosis (MS) have been considered high-risk subjects in most countries and prioritized for COVID-19 vaccination. However, the management of MS during the COVID-19 pandemic has represented a new challenge for MS specialists, particularly because of the initial lack of guidelines and differing recommendations. Despite an initial hesitation in prescribing disease-modifying drugs (DMDs) in naïve and already treated patients with MS, most national neurology associations and organizations agree on not stopping treatment. However, care is needed especially for patients treated with immunedepleting drugs, which also require some attentions in programming vaccine
\end{abstract}

Simona Toscano and Clara G. Chisari have contributed equally to the manuscript.

S. Toscano · C. G. Chisari · F. Patti ( $)$

Department G. F. Ingrassia, Section of

Neurosciences, University of Catania, Via Santa

Sofia 78, 95123 Catania, Italy

e-mail: patti@unict.it administration. Many discoveries and new research results have accumulated in a short time on COVID-19, resulting in a need for summarizing the existing evidence on this topic. In this review, we describe the latest research results on the immunological aspects of SARS-CoV-2 infection speculating about their impact on COVID-19 vaccines' mechanisms of action and focused on the management of MS during the COVID pandemic according to the most recent guidelines and recommendations. Finally, the efficacy of COVID-19 and other well-known vaccines against infectious disease in patients with MS on DMDs is discussed.

Keywords: Multiple

sclerosis;

COVID-19;

Disease-modifying treatment; Vaccines; 


\section{Key Summary Points}

In patients with multiple sclerosis (MS), older age, male sex, comorbidities, higher Expanded Disability Status Scale and treatment with anti-CD20 ${ }^{+}$monoclonal antibodies are risk factors for a severe coronavirus disease 19 (COVID-19) course.

Interferon beta (IFN $\beta$ ) has been associated with a decreased risk for COVID-19, and defects in IFN immunity could be a risk factor for a severe COVID-19 course.

Most of the international and national recommendations agree on not stopping disease-modifying drugs in already treated patients with MS, but risks and benefits of starting a treatment with a particular drug should be considered in naïve patients.

Patients with MS should vaccinate as soon as possible against SARS-CoV-2. For patients treated with ocrelizumab, rituximab and alemtuzumab, timing should be discussed with the MS specialist to maximize the effectiveness of the COVID-19 vaccine.

There is no currently evidence that the currently available COVID-19 vaccines may lead to clinical relapses in patients with MS.

Patients with MS should vaccinate against SARS-CoV-2 as soon as possible with the available vaccines, which are safe and effective in protecting against COVID-19.

\section{INTRODUCTION}

The coronavirus disease 19 (COVID-19) pandemic caused by the severe acute respiratory syndrome coronavirus-2 (SARS-CoV-2) has completely dominated the social, political, economic and health scenario since it was declared by the World Health Organization
(WHO) on 11 March 2020 [1]. By the end of 2020, WHO had already confirmed more than 82.8 million cases and about 1.9 million deaths worldwide [2], and the first COVID-19 vaccine had received conditional marketing authorization by the Food and Drug Administration (FDA) and the European Medicines Agency (EMA) $[3,4]$.

Most people, particularly young and healthy subjects, experienced only the first phase of COVID-19, characterized by no symptoms or mild flu-like ones. However, SARS-CoV-2 infection can lead to the development of a bilateral interstitial pneumonia with respiratory failure and, in the most severe cases, to a hyper-inflammatory state driven by a cytokine storm, possibly presenting with sepsis, disseminated intravascular coagulation and multiorgan failure $[5,6]$.

Different vaccination strategies have been adopted by almost all countries in the world. Almost everywhere priority has been given to the most vulnerable subjects, at high risk for complications associated with COVID-19 due to older age or significant comorbidities.

Among them, people affected by multiple sclerosis (pwMS) have been officially regarded as high-risk subjects in several countries and have been generally prioritized for COVID-19 vaccination [7]. Since most pwMS are on diseasemodifying treatments (DMTs) and 15 vaccines are currently used in at least one country among 115 vaccine candidates [8], some questions have arisen: which vaccines should be recommended and how should DMTs be managed in pwMS in the COVID-19 era?

This article is based on previously conducted studies and does not contain any new studies with human participants or animals performed by any of the authors.

\section{IMMUNOLOGICAL CONSIDERATIONS ABOUT COVID- 19}

SARS-CoV-2 belongs to a group of enveloped single-strand RNA viruses, called coronaviruses, as well as SARS-CoV and Middle East respiratory syndrome coronavirus (MERS-CoV). They are 
characterized by four structural proteins, including envelope, membrane, nucleocapsid $(\mathrm{N})$ and spike (S) proteins [9]. In recent months, several virus variants have spread worldwide, some of them characterized by an increase in transmissibility and a reduced response to the currently available vaccines [10].

The infection by SARS-CoV-2 initially and mainly involves the respiratory tracts through interaction between the angiotensin-converting enzyme 2 (ACE2) receptor expressed in the bronchial and alveolar epitelium and viral $\mathrm{S}$ protein [11]. The virus seems to suppress the attempt of the innate immune system to control the infection, leading to a protracted presymptomatic period (2-12 days) with uncontrolled viral replication, particularly observed when the activation of $\mathrm{CD}^{+} \mathrm{T}$ cells is delayed. In vulnerable subjects, this may favor a dysregulated inflammatory response leading to acute respiratory distress syndrome and potentially life-threatening cytokine release syndrome with consequent heart failure and multiorgan failure [12].

Humoral response, mainly against $\mathrm{S}$ and $\mathrm{N}$ protein in natural adaptive immunity, develops after 1-2 weeks and seems to be higher and more sustained in symptomatic compared with asymptomatic subjects [13]. The neutralizing antibody titer that can be sufficient to protect against SARS-CoV-2 infection is not known, nor is the lifetime of the humoral response [11].

It seems that $\mathrm{T}$ cell-mediated immunity is crucial, as is the humoral immune response, in protecting against SARS-CoV-2, leading to major implications in COVID-19 vaccination design and development [14]. In a study involving 78 patients who recovered from SARSCoV-2 infection, a comparable $\mathrm{T}$ cell immune response was quantified through interferon- $\gamma$ ELISpot in both patients with high and undetectable IgG against $S$ protein [15]. The same technique was used in another study, reporting a significantly higher $\mathrm{T}$ cell immune response in convalescent patients compared with healthy donors, with the additional observation of a trend toward an increased frequency of NK cells in follow-up patients compared with newly discharged ones [16]. T cell receptor-dependent activation-induced marker assays were used in another study to detect functional circulating SARS-CoV-2-specific CD4 ${ }^{+}$and $\mathrm{CD}^{+}{ }^{+} \mathrm{T}$ cells in patients who recovered from COVID-19, which were identified respectively in about $70 \%$ and $100 \%$ of patients [17].

Among T cell-mediated immunity, the role of $\mathrm{T}$ regulatory cells (Tregs), a subset of $\mathrm{CD} 4^{+} \mathrm{T}$ cells, is emerging as particularly crucial. Tregs exert a protective role in controlling tissue damage due to the immune response to viral infections, as pointed out in other studies focusing on respiratory syncytial virus infection [18], herpes simplex virus [19], coronavirus-induced encephalitis [20] and HCV-induced liver injury [21]. Indeed, Tregs can shift the balance between the effector and the regulatory functions toward a downregulation of antiviral $\mathrm{T}$ cell responses, preventing the hyperactivation of the immune system and the consequent lung injury and cytokine storm [22]. Several recent studies reported a lower level of circulating Treg in patients who developed severe COVID-19 compared with patients exhibiting a mild or moderate course [22]. Moreover, COVID-19 patients exhibited higher levels of Treg compared with healthy controls [23, 24], but no differences were observed in COVID-19 patients before and after the age of 45 years [25]. It could be speculated that the efficacy of currently available vaccines against COVID-19 may be partly related to the expansion of Tregs and to the generation of a memory pool of this subset of $\mathrm{CD}^{+} \mathrm{T}$ cells [26]. Indeed, Tregs may prevent a severe COVID-19 course in vaccinated patients in the event of a successive infection by SARS-CoV-2 (Fig. 1).

\section{MULTIPLE SCLEROSIS AND COVID- 19}

\section{Risk of SARS-CoV-2 infection and COVID- 19 course in MS}

MS has been associated with a generally higher infection risk and a two-fold higher rate of hospitalized infections, especially urinary tract, pulmonary, skin and opportunistic infections [27-29]. As for other autoimmune diseases [30], the increased risk could be related to both a 


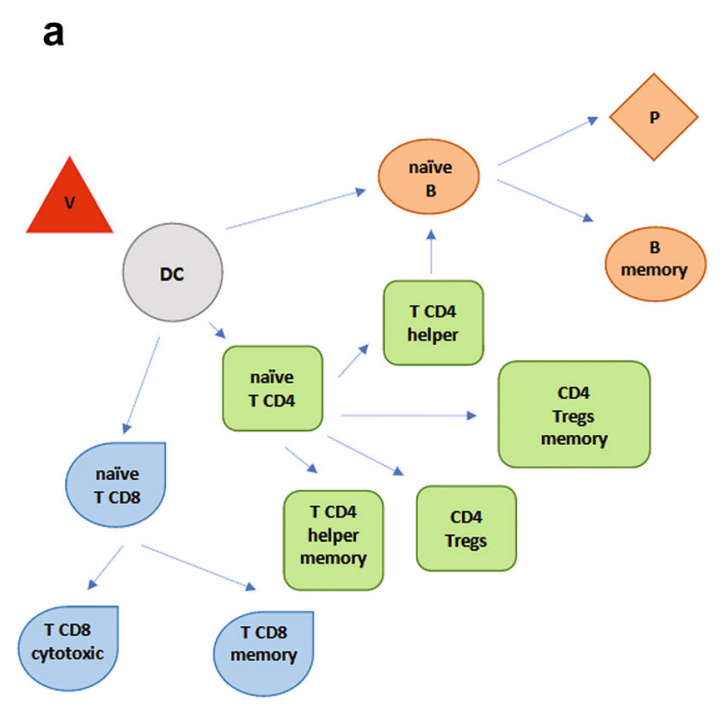

Fig. 1 Development of T-cell and B-cell response after vaccination against SARS-CoV-2 and subsequent activation of the immune system in case of infection. The administration of vaccines against SARS-CoV-2 (V) determines the activation of dendritic cells (DC), with subsequent antigen processing and presentation to naïve B, T CD4+ and T CD8+ lymphocytes (a). Naïve B cells differentiate into plasma cells $(\mathrm{P})$, leading to antibody production, and $\mathrm{B}$ memory cells. Naïve T CD8+ cells differentiate into memory and cytotoxic cells. Naïve $T$ CD4+ cells, including a subset of Tregs, differentiate into memory and effector T cells ( $\mathrm{T}$ CD4+ helper and Tregs). T CD4+ helpers support the differentiation of B cells into plasma cells, favoring the humoral immune response.

disease-related dysregulation of the immune system and the use of immunomodulatory or immunosuppressive drugs [31].

Several studies and data from clinical trials have confirmed an increased infection risk over time only for some DMTs, including natalizumab (NTZ), fingolimod (FTY), ocrelizumab (OCR), alemtuzumab (ALM) and cladribine (CDA) as well as for immunosuppressive drugs and rituximab (RTX), used off-label for MS treatment [32, 33]. In addition, some recent registry- and population-based retrospective studies attributed the lowest infection risk to injectable DMTs (interferon beta, IFN $\beta$, and

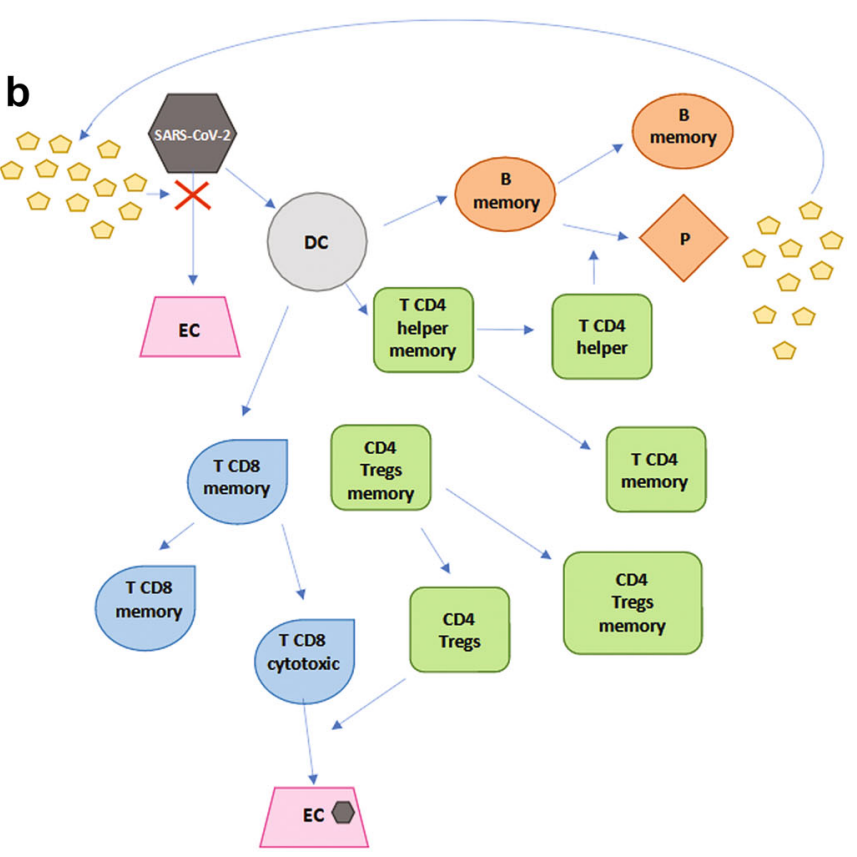

When SARS-CoV-2 infection occurs in a vaccinated subject, the virus initially enters the upper airway epithelial cells (ECs) (b). Memory B cells are able to differentiate into plasma cells $(\mathrm{P})$ with the support of T CD4+ helper cells, leading to antibody production and to regeneration of the pool of memory B cells. Memory T CD8+ cells differentiate into $T$ cytotoxic cells, able to destroy infected cells, and regenerate the pool of memory T CD8+ cells. Tregs modulate the immune response by downregulating antiviral $\mathrm{T}$ cell responses, preventing the hyperactivation of the immune system and the consequent tissue damage and cytokine storm driven by $\mathrm{T}$ cells, leading to severe COVID-19

glatiramer acetate, GA) [34, 35] and the highest risk to RTX [34], with some controversies over NTZ and FTY [34, 35].

Nevertheless, several studies investigating SARS-CoV-2 infection in pwMS have not detected an increased risk of infection in these patients [36-38], nor in those suffering from other systemic autoimmune diseases [39], but a higher risk of hospitalization has been reported [36].

In a retrospective study involving 758 subjects, pwMS exhibited similar incidence, outcomes and risk factors for COVID-19 compared to the general population [38]. In the MS 
cohort, age, contact with a confirmed case, MS duration and time exposure to an anti-CD20 ${ }^{+}$ treatment were independent risk factors for COVID-19. Among them, only age was associated with a severe course of COVID-19.

An international study involving $>30,000$ pwMS identified obesity, Black/African ancestry and comorbidities as risk factors for SARS-CoV-2 infection, without any differences between patients and the general population [31].

In a French multicenter, retrospective, observational study involving 347 pwMS infected with SARS-CoV-2, a higher risk of severe COVID-19 was associated with older age, obesity, male sex and higher EDSS [40]. Noticeably, cardiovascular and pulmonary comorbidities, as well as diabetes and obesity, were reported with high frequency in subjects with severe COVID19, while no association between severe COVID-19 and any DMTs emerged in this study. However, in a successive pooled analysis including two large cohorts of patients from Italy and France (1066 and 721 patients, respectively), treatment with anti-CD20 ${ }^{+} \mathrm{mAbs}$ was associated with a two-fold increased risk of a severe COVID-19 course, while a protective role of IFN $\beta$ emerged [41].

In this regard, a role of auto-antibodies (auto-Abs) against type I IFN or monogenic defects at loci involved in type I IFN immunity has been recently claimed as a risk factor for a life-threatening COVID-19 course $[42,43]$. This has called into question the potential beneficial effect of treatment with IFN $\beta$ in pwMS.

\section{Management of MS during the COVID-19 pandemic}

So far, results from several studies on the impact of DMTs on the COVID-19 disease course have varied, and the debate is still open. On the one hand, the involvement of an exaggerated immune response in severe COVID-19 cases has emerged, raising doubts about the effective risk attributable to DMTs [44]. On the other hand, data are limited, and the benefit-risk ratio of stopping treatment possibly causing a rebound disease activity has to be taken into account [45].
In this context, a change in the frequency of DMT prescription during the SARS-CoV-2 pandemic was expected in clinical practice and has been observed. The European Committee for Treatment and Research in Multiple Sclerosis (ECTRIMS) conducted an online survey between March and July 2020, completed by 360 neurologists from 52 countries [46]. Changes in DMT management were reported by $70 \%$, with $23 \%$ preferring to avoid immune-depleting drugs in naïve pwMS during the pandemic and $43 \%$ considering postponing further administrations of anti-CD $20^{+} \mathrm{mAbs}$ in patients already treated with these DMTs. No particular concerns were declared about the use of IFN $\beta$ and GA nor of DMF, TFM and FTY in patients who did not exhibit moderate-to-severe lymphopenia. Noticeably, the activation ex novo of new strategies, specifically telemedicine, to manage and follow-up pwMS despite COVID-19 restrictions was reported by $73 \%$ and implemented by $17 \%$ of neurologists.

In another survey administered to 243 US and Canadian neuroimmunology-focused neurologists, 54\% considered some DMTs as safer than others, particularly GA (95\%), IFN $\beta$ (80\%) and TFM (50\%) [47]. Conversely, several neurologists reported avoiding the prescription of certain DMTs, especially ALM (61\%), CDA (47\%), OCR (38\%), RTX (35\%) and NTZ (34\%), while $4 \%$ considered not starting any DMTs.

Similar results were reported by another nationwide survey involving 41 neurologists, who reported the interruption of treatment with ALM (21.4\%), CDA (11.9\%), OCR and RTX (16.7\%) among their pwMS, while $38.1 \%$ considered the adoption of extended dosing intervals for NTZ [48].

A Dutch study involving 86 pwMS confirmed no associations between DMT and COVID-19 disease course nor between lymphocyte count and disease severity [49]. Furthermore, a community-based prospective observational study, developed as part of the UK MS Register, confirmed no differences in DMT use among pwMS with COVID-19 [37], while the use of IFN $\beta$ has been even associated with a decreased risk of COVID-19 in several studies [31, 41, 50-52].

Similarly, the North American Registry of MS reported a minor risk of admission to intensive 
care units (ICUs) in pwMS on DMF and NTZ treatment compared with untreated subjects [53]. Differently, in this MS cohort, the use of steroid treatment in the prior 2 months emerged as a risk factor for hospitalization and fatal course.

Whereas an acceptable safety profile emerged for the majority of DMTs toward COVID-19 in several studies, the use of anti$\mathrm{CD}^{2}{ }^{+}$monoclonal antibodies (mAbs) has recently emerged as a risk factor for severe COVID-19. In a large retrospective registerbased study conducted by the Multiple Sclerosis and COVID-19 (MuSC-19) group, treatment with RTX or OCR was significantly associated with an increased risk of severe COVID-19, and a worse outcome was also related to high-dose steroid treatment occurring in the previous month [50]. Other studies reported the use of anti-CD20 ${ }^{+}$mAbs, especially after long treatment exposure, as an independent risk factor for COVID-19 [31, 36, 38, 41, 54] and hospitalization [53].

Among pwMS treated with OCR in ten ongoing Roche/Genentech clinical trials up to 31 July 2020, 51 of 4000 patients were identified as confirmed or suspected cases of COVID-19 [55]. Of them, $31.4 \%$ were hospitalized, $19.6 \%$ had a severe course, and $5.9 \%$ died, while $68.6 \%$ had mild or moderate disease, independent from the period of DMT exposure. Additionally, from the OPTUM ${ }^{\circledR}$ database, among an estimated 97,502 subjects treated with OCR in the US, 48 pwMS were confirmed to have COVID19 , with an incidence rate of $0.05 \%$ [55].

Differently, no severe COVID-19 cases have been observed in subjects treated with ALM, despite concerns being raised for pwMS treated with this DMT due to the related prominent lymphopenia [56, 57].

Comprehensively, these findings led national neurology associations and organizations to produce guidelines on the management of MS during the COVID-19 pandemic, based on expert consensus statements [58] (Table 1). At first, considering the mechanisms of action and long-lasting effects, most of them advised neurologists to reconsider the use of immunodepleting DMTs in newly diagnosed pwMS and to postpone the redosing between 6 and
12 months [59-62], but these considerations were not univocal [63].

Most of the international and national recommendations agreed on not stopping other DMTs in already treated pwMS, even during active COVID-19 infection, and on favoring the choice of IFN $\beta$, GA and NTZ in naïve pwMS, but always discussing risks and benefits of DMTs for each patient [58].

Opinions about the use of dimethyl fumarate (DMF), teriflunomide (TFM) and FTY in newly diagnosed pwMS have varied, since recommendations by the MS International Federation, the European Multiple Sclerosis Platform and the MS Society of the UK raised some doubts about starting a new treatment with these DMTs during the pandemic [60, 61, 64].

Particular consideration should be made for patients planning to undergo autologous hematopoietic stem cell transplantation (HSCT), often after failure of highly active DMDs [65]. As recommended by the European Society for Blood and Marrow Transplantation (EBMT), all prevention practices implemented during the COVID-19 pandemic should be strictly applied to patients and health care staff and alternative treatments should be considered, since HSCT recipients are at high risk for SARS-CoV-2 infection regardless of the conditioning regimen used [66, 67]. Accordingly, only patients with a clear risk/benefit ratio, not diagnosed with COVID-19 and with no severe comorbidities should undergo HSCT during the current pandemic [67]. In a recent retrospective study conducted by Sharma and colleagues, among 318 HSCT recipients (134 autologous, 184 allogenic) diagnosed with COVID-19, 14\% of patients required mechanical ventilation and $21 \%$ died, with an overall survival probability at 30 days after COVID-19 diagnosis of 67\% [68].

\section{DMTS AND VACCINES}

Considering the scarce availability of data on the response of pwMS to COVID-19 vaccines, previous results from clinical trials and realworld experience exploring the response to other vaccines provided a basis for estimating their safety and efficacy profile (Table 2). 
Table 1 Recommendations from main national neurology associations and organizations for the management of MS during COVID-19 pandemic

\section{DMDs Recommendations}

IFN $\beta \quad$ Any adjustments required in newly diagnosed pwMS, in those who currently take the drug or in patients with COVID-19 [59-61, 132-135]

GA Any adjustments required in newly diagnosed pwMS, in those who currently take the drug or in patients with COVID-19 [59-61, 132-135]

DMF Any adjustments required in newly diagnosed pwMS, in those who currently take the drug or in patients with COVID-19 [59, 60, 134, 135]

More restrictive protection measures should be considered for pwMS treated with this DMT [59]

Patients currently taking this treatment should continue, considering more frequent monitoring of immune cell counts $[132,133]$

TFM Any adjustments required in newly diagnosed pwMS, in those who currently take the drug or in patients with COVID-19 [59, 60, 134, 135]

More restrictive protection measures should be considered for pwMS treated with this DMT [59]

Patients currently taking this treatment should continue, considering more frequent monitoring of immune cell counts $[132,133]$

Consider the risk/benefit ratio of starting a new treatment with this drug [59]

FTY Patients currently taking this treatment should continue [134], considering more frequent monitoring of immune cell counts [132, 133], and vaccinate as soon as possible [61]

Any adjustments required in pwMS currently taking the drug [59]

Consider initiating treatment after the patient is fully vaccinated [61]

Consider the risk/benefit ratio of starting a new treatment with this drug [59]

More restrictive protection measures should be considered for pwMS treated with this DMT [59]

NTZ Any adjustments required in newly diagnosed pwMS, in those who currently take the drug or in patients with COVID-19 [59, 60, 134, 135]

Patients currently taking this treatment should continue, considering more frequent monitoring of immune cell counts $[132,133]$

Consider home infusion in regions with high COVID-19 incidence [136]

Extended interval dosing could be considered [135]

OCR Consider delaying treatment initiation in older patients and in those with comorbidities $[132,133,135,136]$

Consider on a case-by-case basis the risk/benefit profile in pwMS with additional risk factors for worse outcomes from COVID-19 (age > 60 years, male gender, comorbidities, higher levels of disability) [59, 132, 134]

Retreatments should be administered if clinical indication is met [134]

More restrictive protection measures should be considered for pwMS treated with this DMT [59, 132, 133]

Consider the risk/benefit in PPMS patients [135]

Consider starting treatment after full vaccination [61] 
Table 1 continued

\section{DMDs Recommendations}

Consider home infusion in regions with high COVID-19 incidence [136]

RTX Consider delaying treatment initiation in older patients and in those with comorbidities [132, 133, 136]

Consider on a case-by-case basis the risk/benefit profile in pwMS with additional risk factors for worse outcomes from COVID-19 (age > 60 years, male gender, comorbidities, higher levels of disability) [59, 132, 134]

Retreatments should be administered if clinical indication is met [134]

More restrictive protection measures should be considered for pwMS treated with this DMT [59, 132, 133]

Consider home infusion in regions with high COVID-19 incidence [136]

ALM Consider delaying treatment initiation in older patients and in those with comorbidities [132, 133, 136]

Consider to initiate treatment after the patient is fully vaccinated [61]

Consider on a case-by-case basis the risk/benefit profile in pwMS. Retreatments should be administered if clinical indication is met $[59,134,135]$

More restrictive protection measures should be considered for pwMS treated with this DMT [59, 132, 133]

Consider home infusion in regions with high COVID-19 incidence [136]

CDA Consider delaying treatment initiation in older patients and in those with comorbidities if disease activity allows it $[133,136]$

Consider initiating treatment after the patient is fully vaccinated [61]

Consider on a case-by-case basis the risk/benefit profile in pwMS. Retreatments should be administered if clinical indication is met $[59,134,135]$

More restrictive protection measures should be considered for pwMS treated with this DMT [59, 132, 133]

BAF Consider the risk/benefit ratio of starting a new treatment with this drug [59]

More restrictive protection measures should be considered for pwMS treated with this DMT [59]

Consider initiating treatment after the patient is fully vaccinated [61]

Patients currently taking this treatment should continue, considering more frequent monitoring of immune cell counts $[59,132,133]$

$D M T$ disease-modifying treatment, $p w M S$ patients with multiple sclerosis, $I F N \beta$ interferon beta, $G A$ glatiramer acetate, $D M F$ dimethyl fumarate, $T F M$ teriflunomide, $F T Y$ fingolimod, $N T Z$ natalizumab, $O C R$ ocrelizumab, $R T X$ rituximab, $A L M$ alemtuzumab, $C D A$ cladribine, $B A F$ siponimod

In this regard, IFN $\beta$ and GA were not expected to decrease the humoral immune response after COVID-19 vaccination, based on the comparable rate of immunization developed by treated patients and controls after vaccinations against influenza viruses [32, 69-72]. Similar considerations have been assumed for pwMS on TFM and DMF, who generally did not exhibit a decreased serological response to vaccines compared with IFN $\beta$-treated patients [73, 74].

Although live-attenuated vaccines should not be administered to pwMS on FTY, inactivated ones do not raise particular safety concerns but may be less effective when administered during FTY and within 2 months from the last administration [70, 72, 75, 76]. Differently, the effectiveness of influenza 
vaccines in pwMS treated with CDA does not seem to be reduced [77, 78].

Some evidence exists about a decreased serological immune response to vaccines in pwMS treated with NTZ compared with healthy controls [70, 79, 80]. Although a loss of effectiveness is expected when vaccines are administered during treatment with ALM and within 6 months from the last dosing, a pilot casecontrol study reported comparable humoral immune responses after the administration of several vaccines in pwMS treated with ALM and controls [81, 82]. PwMS treated with ALM should not receive live-attenuated vaccines during and within the 6 weeks from the last infusion, and similar safety recommendations are provided for treatment with the anti-CD20 ${ }^{+}$ mAbs OCR and RTX, which also affect the development of an adequate humoral immune response toward several vaccines [75, 83-85].

According to EBMT recommendations [86], patients should be preferably vaccinated against preventable infections before undergoing HSCT; in any event, a precise timing of immunization should be considered. Several studies confirmed that antibody titers reduce after HSCT and in the following years $[87,88]$ and that revaccination or additional vaccine doses should be considered after HSCT [89], particularly against some infections which are more frequent and severe in transplanted patients (pneumococcus, Haemophilus influenzae type b, influenza, varicella-zoster virus) [86]. As a general rule, the humoral response to vaccines is low during the first 6 months after HSCT and increases from 25 to $60 \%$ when immunization occurs after at least 2 years from immunosuppression [86]. Moreover, live-attenuated vaccines should not be administered except in special conditions.

\section{MULTIPLE SCLEROSIS AND COVID- 19 VACCINES}

\section{COVID-19 Vaccines}

Since the end of 2020, more than a billion COVID-19 vaccine doses have been administered worldwide, with different national policies and vaccination strategies. A huge number of molecules with different mechanisms of action has been explored, and $>20$ vaccines were approved by at least one country in the first half of 2021, including inactivated, non-replicating viral vector, protein subunit and messenger RNA (mRNA) vaccines [8]. All the approved vaccines require parenteral administration and target the development of neutralizing antibodies against $\mathrm{S}$ protein among the four structural viral proteins, since they are only able to confer protection against SARS-CoV infections [90]. Differently, while viral vector and live-attenuated vaccines seem suitable to trigger an adequate $\mathrm{CD}^{+} \mathrm{T}$ cell-mediated immune response, inactivated, protein subunit and virus-like particle vaccines do not. Nucleic acid-based vaccines may also trigger a moderate $\mathrm{T}$ cell-mediated response, as reported for the so far approved mRNA vaccines, depending on the chosen adjuvant and formulation [11]. This is a focal point since the currently available recommendations for MS patients only consider the humoral immune response to COVID-19 vaccines, although vaccination may protect patients under B-cell-depleting treatments with no humoral response by inducing a memory pool of T cells against SARS-CoV-2.

mRNA vaccines encoding $S$ protein have been developed by Pfizer/BioNTech (BNT162b2, Comirnaty $\left.{ }^{\circledR}\right)$ and Moderna (mRNA-1273, Spikevax $\left.{ }^{\circledR}\right)$. These vaccines do not contain any live materials, consisting of lipid nanoparticles delivering mRNA into host cells, where it guides the synthesis of SARS-CoV-2 S antigen, to trigger the cellular and serological immune response [57, 91]. Both received conditional marketing authorization from the Commission of EMA in December 2020 and January 2021 $[3,92]$, respectively, and by FDA in the US in December 2020 [4, 93]. A very high efficacy rate in preventing COVID-19 infection of $94 \%$ and $95 \%$ has been reported in phase 3 trials for the two-dose regimen of mRNA-1273 $\AA$ and Comirnaty ${ }^{\circledR}$, respectively, whose adverse events mostly include headache, mild-to-moderate pain at the injection site and fatigue [94, 95] (Table 3).

FDA and EMA also approved the COVID-19 viral vector vaccine Ad26.COV2.S developed by 
Table 2 Immune response to vaccines in patients treated with DMDs

IFN $\beta$ An adequate humoral response (hemagglutination titer $\geq 40$ ) to influenza A virus subtypes H1N1 and H3N2 vaccines and influenza $B$ vaccine was detected in a similar proportion of patients on IFN $\beta$-1a and controls [69]

High seroprotection rates $(>84 \%)$ after trivalent seasonal influenza vaccination $(\mathrm{H} 1 \mathrm{~N} 1, \mathrm{H} 3 \mathrm{~N} 2$ and influenza $\mathrm{B})$ in IFN $\beta$-treated patients [70]

IFN $\beta$ did not decrease seroprotection toward pandemic H1N1 (swine flu) and seasonal influenza vaccination compared with controls (44.4\% vs 43.5\%) [71]

No significant differences in rates of protection against H1N1 for patients treated with IFN $\beta$-1a/1b compared with controls at 3, 6 and 12 months [72]

GA No significant differences in rates of protection against H1N1 for patients treated with GA compared with controls at 3, 6 and 12 months [72]

High seroprotection rates against influenza A subtype H3N2 (73.1\%) and influenza B (80.8\%), comparable to patients on IFN $\beta[70]$

Reduced seroprotection to seasonal influenza and swine flu was reported in patients on GA compared with controls $(21.6 \%$ vs $43.5 \%)[71]$

DMF In DMF compared with IFN $\beta$-treated patients, responder rates ( $\geq$ twofold rise) to tetanus-diphtheria toxoid, pneumococcal polyvalent and meningococcal tetravalent oligosaccharide vaccines were comparable [74]

TFM Seroprotection rates after influenza vaccination type H1N1 were comparable for TFM- and IFN $\beta$-treated patients [73]

For H3N2, fewer patients in the TFM group exhibited seroprotection to H3N2 compared with IFN- $\beta-1$ group (61\% vs $82 \%)[73]$

FTY The responder rates (seroconversion or increase $\geq$ fourfold in antibody titers) for influenza vaccine in FTY and placebo groups were $54 \%$ vs $85 \%$ at 3 weeks and $43 \%$ vs $75 \%$ at 6 weeks post-vaccination [76]

The responder rates (seroconversion or increase $\geq$ fourfold in antibody titers) for tetanus toxoid booster vaccine in FTY and placebo groups were $40 \%$ vs $61 \%$ at 3 weeks and $38 \%$ vs $49 \%$ at 6 weeks post-vaccination [76]

Decreased seroprotection against H1N1 in NTZ-treated patients compared with IFN $\beta$, GA and untreated patients at 3, 6 and 12 months [72]

Decreased seroprotection against influenza A subtype H3N2 (33.3\%) and influenza B (66.7\%) was reported compared with patients on IFN $\beta$ and GA [70]

NTZ Decreased seroprotection against influenza A subtype H3N2 (28.6\%) and influenza B (57.1\%) was reported compared with patients on IFN $\beta$ and GA [70]

Decreased seroprotection against H1N1 in NTZ-treated patients compared with IFN $\beta$, GA and untreated patients at 3 and 6 months, not at 12 months [72]

Humoral responses against influenza B and influenza A vaccines were not different between NTZ-treated patients and healthy controls [79]

A reduced seroprotection to seasonal influenza and swine flu was reported in patients on GA compared with controls (23.5\% vs $43.5 \%)$ [71]

NTZ-treated patients exhibited similar levels of anti-tetanus toxoid IgG antibodies compared with untreated patients [80] 
Table 2 continued

OCR Humoral response to tetanus toxoid vaccine at 8 weeks was decreased in OCR-treated patients compared with untreated or IFN $\beta$-treated patients $(23.9 \%$ vs $54.5 \%)$, with vaccine administered 12 weeks after the last administration [83]

Positive response rate to $\geq 5$ serotypes in $23 \mathrm{PPV}$ at 4 weeks was observed in $71.6 \%$ in OCR-treated patients and $100 \%$ in the control group, with vaccine administered 12 weeks after the last administration [83]

Seroprotection rates at 4 weeks against 5 influenza strains ranged from $55.6 \%$ to $80.0 \%$ in OCR-treated group and $75.0 \%$ to $97.0 \%$ in the control group, with vaccine administered 12 weeks after the last administration [83]

RTX RTX-treated patients did not exhibit a significant increase of IgM and IgG H1N1- and H3N2-specific antibodies compared with healthy controls. In patients treated with RTX 6-10 months before vaccination, IgG response to vaccination was restored, but not IgM response [84]

ALM Vaccine responses in ALM-treated patients, within 6 months of treatment, were normal toward tetanus, diphtheria and polio vaccines, meningococcus $\mathrm{C}$, pneumococcal antigens [82]

CDA Adequate antibody titers developed when vaccination against influenza occurred early (1.5-6 months of the first year of treatment or $1-4.5$ of the second year) or late (months $8.5-10.5$ of year 1 ) $[77,78]$

$I F N \beta$ interferon beta, GA glatiramer acetate, $D M F$ dimethyl fumarate, TFM teriflunomide, $F T Y$ fingolimod, NTZ natalizumab, $O C R$ ocrelizumab, $R T X$ rituximab, $A L M$ alemtuzumab, $C D A$ cladribine

Janssen Pharmaceutica NV (in February and March 2021, respectively), while only EMA approved ChAdOx1-S recombinant viral vector vaccine by AstraZeneca, now known as Vaxzevria, in January 2021 [96-98]. Non-replicating adenoviruses act as a carrier for the $S$ gene of SARS-CoV-2, needed to ultimately synthetize $S$ protein and stimulate both the innate and the adaptive immune responses [99]. ChAdOx1-S recombinant vaccine exhibited an efficacy of $62.1 \%$ after two standard doses [100], while Ad26.COV2.S had efficacy of $66.9 \%$ against symptomatic moderate and severe SARS-CoV-2 infection [101] (Table 3).

EMA also started rolling review of COVID-19 vaccines from Novavax (protein-based), Curevac AG (mRNA) and Gamaleya's Sputnik V (viral vector, approved in Russia in August 2020) for formal marketing authorization application $[102,103]$.

Currently, 41 vaccines are under assessment in phase 3 clinical trials, 56 in phase 2 and 36 in phase 1 , while trials on 5 vaccines have been interrupted. Among them, further mechanisms of action have been tested, such as replicating viral vector, DNA and virus-like particle (VLP) vaccines [8].

\section{Safety and efficacy considerations on COVID-19 vaccines and MS}

Actually, no particular safety concerns have arisen related to the use of the currently approved COVID-19 vaccines in pwMS on DMT, also considering that no live-attenuated COVID-19 vaccines have been approved so far. Moreover, in a recent study involving 555 pwMS who underwent vaccination with BNT162b2 vaccine, no increase of relapse activity emerged [104]. As further confirmation, a recent prospective study including 324 patients with MS who received BNT162b2 vaccine did not detect an increased risk of clinical relapses during the 2-month short-term followup after the first vaccine dose [105].

The concurrent use of DMTs, though, may lead to a decrease in the effectiveness of COVID19 vaccines. Comprehensively, risks related to SARS-CoV-2 infection, including COVID-19-related complications and MS exacerbations, led to the unanimously accepted recommendation to not stop current DMT and to vaccinate as early as possible with the available COVID-19 vaccines [106]. 
Table 3 Characteristics of currently approved vaccines against SARS-CoV-2 by the EMA and FDA

\begin{tabular}{|c|c|c|c|c|c|c|}
\hline Vaccine & Type & Age & Efficacy & Doses & Approval & $\begin{array}{l}\text { FDA/EMA } \\
\text { warnings }\end{array}$ \\
\hline \multirow[t]{5}{*}{$\begin{array}{l}\text { Comirnaty (Pfizer- } \\
\text { BionTech) }\end{array}$} & \multirow[t]{5}{*}{ mRNA } & \multirow[t]{5}{*}{$\geq 12$} & $\begin{array}{l}95 \% \text { against severe disease in } \\
\text { phase } 3 \text { trials }[94]\end{array}$ & $\begin{array}{l}2 \text { (21 days } \\
\text { apart) }\end{array}$ & $\begin{array}{l}\text { EMA: } \\
\text { December } \\
2020[3]\end{array}$ & \multirow[t]{5}{*}{$\begin{array}{l}\text { Myocarditis, } \\
\text { pericarditis } \\
{[141]}\end{array}$} \\
\hline & & & $\begin{array}{l}\text { 84.3\% against hospitalization } \\
\text { (real-world evidence) [137] }\end{array}$ & $\begin{array}{l}\text { Fully effective } \\
\text { after } 2 \text { weeks } \\
\text { from the } 2 \text { nd } \\
\text { shot }\end{array}$ & $\begin{array}{l}\text { FDA: } \\
\text { December } \\
2020[4]\end{array}$ & \\
\hline & & & $\begin{array}{l}\text { 88\% against symptomatic } \\
\text { disease (Delta variant) } \\
{[138]}\end{array}$ & & & \\
\hline & & & $\begin{array}{l}42 \% \text { against symptomatic } \\
\text { disease (Delta variant) } \\
{[139]}\end{array}$ & & & \\
\hline & & & $\begin{array}{l}\text { 96\% against hospitalization } \\
\quad \text { (Delta variant) }[140]\end{array}$ & & & \\
\hline \multirow[t]{3}{*}{$\begin{array}{l}\text { Spikevax (ex COVID- } \\
19 \text { vaccine } \\
\text { Moderna) }\end{array}$} & \multirow[t]{3}{*}{ mRNA } & \multirow[t]{3}{*}{$\geq 12$} & $\begin{array}{l}94 \% \text { against symptomatic } \\
\text { disease }(86 \% \text { in } \geq 65 \text { years }) \\
{[95]}\end{array}$ & $\begin{array}{l}2 \text { (28 days } \\
\text { apart) }\end{array}$ & $\begin{array}{l}\text { EMA: } \\
\text { January } \\
2021[92]\end{array}$ & \multirow[t]{3}{*}{$\begin{array}{l}\text { Myocarditis, } \\
\text { pericarditis } \\
{[141]}\end{array}$} \\
\hline & & & $\begin{array}{l}\text { 90\% against symptomatic } \\
\text { disease (real-world } \\
\text { evidence) }[137]\end{array}$ & $\begin{array}{l}\text { Fully effective } \\
\text { after } 2 \text { weeks } \\
\text { from the } 2 \text { nd } \\
\text { shot }\end{array}$ & $\begin{array}{l}\text { FDA: } \\
\text { December } \\
2020[93]\end{array}$ & \\
\hline & & & $\begin{array}{l}\text { 76\% against symptomatic } \\
\text { disease (Delta variant) } \\
{[139]}\end{array}$ & & & \\
\hline \multirow[t]{4}{*}{$\begin{array}{l}\text { Vaxzevria (ex } \\
\text { COVID-19 vaccine } \\
\text { AstraZeneca) }\end{array}$} & \multirow[t]{4}{*}{ NRVV } & \multirow[t]{4}{*}{$\geq 18$} & $\begin{array}{l}62-76 \% \text { against symptomatic } \\
\text { disease }(85 \% \text { in } \geq 65 \text { years }) \\
{[100,142]}\end{array}$ & $\begin{array}{l}2 \text { (4-12 weeks } \\
\text { apart) }\end{array}$ & $\begin{array}{l}\text { EMA: } \\
\text { January } \\
2021[97]\end{array}$ & \multirow[t]{4}{*}{$\begin{array}{l}\text { Blood } \\
\text { clotting } \\
\text { disorders } \\
{[144]}\end{array}$} \\
\hline & & & $\begin{array}{l}\text { 100\% against severe disease } \\
{[142]}\end{array}$ & & $\begin{array}{l}\text { FDA: Not } \\
\text { approved }\end{array}$ & \\
\hline & & & $\begin{array}{l}\text { 62-67\% against symptomatic } \\
\text { disease (Delta variant) } \\
{[138,143]}\end{array}$ & & & \\
\hline & & & $\begin{array}{l}90 \% \text { against hospitalization } \\
\text { (Delta variant) }[140]\end{array}$ & & & \\
\hline
\end{tabular}


Table 3 continued

\begin{tabular}{|c|c|c|c|c|c|c|}
\hline Vaccine & Type & Age & Efficacy & Doses & Approval & $\begin{array}{l}\text { FDA/EMA } \\
\text { warnings }\end{array}$ \\
\hline \multirow[t]{4}{*}{$\begin{array}{l}\text { Janssen } \\
\text { (Johnson\&Johnson) }\end{array}$} & \multirow[t]{4}{*}{ NNVV } & \multirow[t]{4}{*}{$\geq 18$} & $\begin{array}{l}67 \% \text { against symptomatic } \\
\text { disease }[101]\end{array}$ & \multirow[t]{4}{*}{$\begin{array}{l}1 \text { Fully effective } \\
\text { after } 2 \text { weeks }\end{array}$} & $\begin{array}{l}\text { EMA: } \\
\text { March } \\
2021[96]\end{array}$ & $\begin{array}{l}\text { Blood } \\
\text { clotting } \\
\text { disorders } \\
{[148]}\end{array}$ \\
\hline & & & $\begin{array}{l}\text { 85\% against severe disease } \\
\text { (Beta variant; included a } \\
\text { subset of Delta variants) } \\
{[145,146]}\end{array}$ & & \multirow[t]{3}{*}{$\begin{array}{l}\text { FDA: } \\
\text { February } \\
2021[98]\end{array}$} & \multirow[t]{3}{*}{$\begin{array}{l}\text { Guillain- } \\
\text { Barré } \\
\text { syndrome } \\
{[149]}\end{array}$} \\
\hline & & & $\begin{array}{l}72 \% \text { against symptomatic } \\
\text { disease }[147]\end{array}$ & & & \\
\hline & & & $\begin{array}{l}\text { 86\% against severe disease } \\
\quad[147]\end{array}$ & & & \\
\hline
\end{tabular}

$N N R V$ non-replicating viral vector, EMA European Medicine Agency, FDA Food and Drug Administration

Evidence about the effectiveness of COVID19 vaccination in pwMS on different DMTs is sparse. Based on their mechanisms of action and results from previous studies, major doubts could involve cell-depleting therapies (anti$\mathrm{CD}_{20}{ }^{+}$mAbs, ALM and CDA) and FTY. Accordingly, among US and Canadian neurologists participating in an online survey, 80\% agreed that some DMTs may not allow patients to develop an adequate serological immune response after COVID-19 vaccination, particularly referring to anti-CD20 ${ }^{+} \mathrm{mAbs}$ ocrelizumab and rituximab (84\% and $83 \%$ respectively), alemtuzumab (78\%), cladribine $(60 \%)$ and steroid treatment (53\%) [47].

In this regard, previous studies detected reduced antibody titers and frequent seroconversion after vaccination in pwMS treated with anti-CD20 ${ }^{+}$mAbs [107], but other considerations are needed. OCR and RTX selectively target $\mathrm{CD} 20^{+}$antigen expressed on pre-B cells, mature and memory $\mathrm{B}$ cells, leading to their depletion, not affecting innate immunity, $\mathrm{T}$ cells, pre-existing humoral immunity and B cell reconstitution [107, 108]. The effects of anti$\mathrm{CD}^{+} 0^{+}$mAb-related hypogammaglobulinemia on prior immunization are not known
[107, 109]. However, in patients with autoimmune diseases treated with RTX, an adequate recall immune response to influenza vaccines was observed after $\mathrm{CD} 19^{+}$cell recovery, despite a lack of influenza-specific memory B lymphocytes [110].

In this context, a recent international cohort study, conducted as part of the Italian Multiple Sclerosis and COVID-19 (MuSC-19) project on 423 patients, reported a significant association between anti-CD20 ${ }^{+}$treatment and a reduced probability of developing a humoral immune response to SARS-CoV-2 after infection [111], confirming previous evidence from single observations [112] and the results of a casecontrol study involving 24 pwMS treated with OCR in the 6 months preceding SARS-CoV-2 infection [113]. Differently, treatment with other DMDs did not affect the development of antibodies after COVID-19 in the same study [111]. Additionally, preliminary evidence of a decreased humoral response in patients treated with OCR compared with healthy controls after vaccination with BNT162b2 vaccine has recently emerged [114].

Nevertheless, two recent studies showed promising results related to the development of 
an adequate T-cell response in more than 96\% of patients treated with anti-CD20 ${ }^{+}$mAbs, regardless of the low humoral response exhibited after SARS-CoV-2 infection or COVID-19 vaccination $[115,116]$.

As for FTY, a reduced immune response to other vaccines has already been reported [117] as well as evidence of an altered cellular and humoral immune response after SARS-CoV-2 vaccination in a patient treated with this DMT [118]. Despite some concerns about the development of an adequate response after COVID19 vaccines in such patients [119], these should be administered to patients, possibly encouraging the evaluation of the immunization state after at least 2 weeks from the last dose.

Differently, no differences in the development of a robust humoral response were detected between patients treated with NTZ and healthy controls 7 days after the second dose of BNT162b2 mRNA vaccine [120].

Confirming these preliminary considerations, a recent study explored the development of a protective humoral response in 125 pwMS on different DMTs and in 47 healthy controls within 4.5-6.5 weeks following the second dose of BNT162b2-COVID-19 vaccine [121]. PwMS treated with CDA, untreated ones and healthy controls exhibited comparable SARS-CoV-2 IgG against $S$ protein, while $22.7 \%$ of those on OCR and only $3.8 \%$ of patients on FTY developed a protective humoral response.

Robust evidence is still lacking on the durability of protection induced by COVID-19 vaccines. A recent study involving 27 healthy participants revealed a substantial reduction of neutralizing SARS-CoV-2 IgG at 3 months postvaccination with mRNA vaccines against all variants [122]. In this regard, Pfizer/BioNTech disclosed data coming from more than 44,000 enrolled volunteers, detecting a decrease from 96 to $84 \%$ in BNT162b2 vaccine efficacy over 6 months, with an average drop of $6 \%$ every 2 months after vaccination [123]. Similarly, mRNA-1273 vaccine developed by Moderna showed only a slight wane in efficacy over 6 months (from 100 to $96 \%$ against Alpha and Delta variants) [124].

However, a third (booster) dose is supposed to be required and was already authorized by
FDA on 12 August 2021 and recommended by US Centers for Disease Control and Prevention and the Joint Committee on Vaccination and Immunisation in the UK for immunocompromised individuals needing further protection from COVID-19 [125-127]. Many other countries have already announced the decision to offer booster doses to vulnerable subjects and the elderly in the coming months, while other are already administering third doses, e.g., Israel and Serbia [128].

\section{Recommendations on COVID-19 vaccination in patients on DMTs}

Currently, the administration of vaccines against SARS-CoV-2 is strongly recommended to all patients with MS and is considered safe, since preliminary evidence has confirmed no increased risk of relapses after vaccination [104]. PwMS have been prioritized for COVID-19 vaccination in many countries as vulnerable subjects and should vaccinate against SARS-CoV-2 as early as possible, with the vaccines available in their countries. All approved vaccines have been demonstrated to be effective in reducing the risk of severe COVID-19 and hospitalization, leaving no doubts about the risk/benefit ratio of vaccination in the current pandemic.

Wherever practicable, to maximize the effectiveness of COVID-19 vaccines, optimizing times for starting new DMTs or administering immune-depleting therapies has been suggested by several national neurology associations and MS organizations [59, 60].

Based on what was already known about vaccines and DMTs, it has been assumed that IFN $\beta$, GA, DMF, TFM and NTZ do not require any adjustments in view of vaccination [60].

No adjustments have been advised for pwMS already taking FTY, ozanimod or siponimod [59]. However, if a new treatment with these drugs has to be started, neurologists could suggest completing COVID-19 vaccination at least 4 weeks before starting therapy [60].

The vaccination strategy for pwMS treated with CDA could rely on very few data until recently. PwMS and neurologists have been advised to consider COVID-19 vaccination at 
least 4 weeks before starting treatment or to delay it at least 12 weeks after the last administration of CDA $[59,60]$ as well as for ALM $[60,129]$. However, based on the recent data from the MS-magnify study [78], it seems that COVID-19 vaccines could be administered 4 weeks after the last intake of cladribine without penalizing effectiveness and safety [57].

Differently, time adjustments are required for patients treated with anti-CD20 ${ }^{+}$mAbs willing to be vaccinated. Particularly, some national guidelines addressed the need to delay vaccination at least 12 weeks after the last administration of OCR (or RTX) or to anticipate vaccination at least 4 weeks before $[57,59,60,130,131]$.

Steroid treatment in pwMS with evidence of disease activity should be temporally outdistanced from the timing of vaccination. Some national organizations such as the Italian Society of Neurology (SIN) suggested administering COVID-19 or any other vaccines to pwMS whose disease has been stable during the last 30 days, not requiring any steroid treatments in the same period. However, if steroids are needed because of MS exacerbations, COVID-19 vaccination should be postponed at least 4 weeks [59]. Differently, the MS International Federation advised considering COVID-19 vaccination after at least 3-5 days from high-dose steroids [60].

There is still no evidence of COVID-19 vaccine efficacy in patients who were subjected to HSCT. However, it is suggested to avoid liveattenuated and replicating viral-vector vaccines and to consider vaccination at least 3 months from HSCT for other vaccine types. Revaccination could be required in patients who were administered COVID-19 vaccines before autologous transplantation [67].

\section{CONCLUSION}

In over a year, the COVID-19 pandemic has claimed more than 3 million victims, particularly among the most vulnerable. Only with the recent start of the vaccination campaign among the general population does achieving control of the current pandemic seem a little closer.
However, many questions are still unanswered. The durability of the adaptive immune response to COVID-19 vaccines is not known, and the effectiveness of the vaccine administration to pwMS on DMTs is currently under evaluation. Moreover, the approved COVID-19 vaccines mainly target the development of the humoral immune response, but the prominent role of the $\mathrm{T}$ cell-mediated immunity in protecting from SARS-CoV-2 infection is emerging.

Among DMTs for the management of MS, anti-CD20 ${ }^{+}$mAbs still cause concerns, since they may both negatively affect the COVID-19 course and preclude the development of an adequate immune response to vaccines. However, much has been done in a short time, and clinical research is very active on this topic.

At present, and until proven otherwise, all pwMS should be advised on COVID-19 risks and preventive measures and all should be recommended to vaccinate as soon as possible with the available vaccines. Moreover, the individual benefit/risk ratio should always be evaluated by physicians in the management of pwMS, particularly for those treated with immune-depleting DMTs.

\section{ACKNOWLEDGEMENTS}

Funding. No funding or sponsorship was received for this study or publication of this article.

Authorship. All named authors meet the International Committee of Medical Journal Editors (ICMJE) criteria for authorship for this article, take responsibility for the integrity of the work as a whole, and have given their approval for this version to be published.

Authors' Contributions. All authors contributed to the study conception and design and to the literature search. The first draft of the manuscript was written by Simona Toscano and Clara Grazia Chisari, and all authors commented on previous versions of the manuscript. The final draft of the manuscript was written by Simona Toscano and Clara Grazia Chisari. All 
authors read and approved the final manuscript.

Disclosures. Simona Toscano received a grant for congress participation from Biogen and TEVA. Clara Grazia Chisari received a grant for congress participation from Almiral, Biogen, Merck Serono, Novartis, Roche, Sanofi and TEVA. Francesco Patti received honoraria for speaking activities from Bayer Schering, Biogen, Merck Serono, Novartis; he was funded by Pfizer and FISM for epidemiological studies; he received a grant for congress participation from Bayer Schering, Biogen, Merck Serono, Novartis, Roche, Sanofi and TEVA.

Compliance with Ethics Guidelines. This article is based on previously conducted studies and does not contain any new studies with human participants or animal performed by any of the authors.

Open Access. This article is licensed under a Creative Commons Attribution-NonCommercial 4.0 International License, which permits any non-commercial use, sharing, adaptation, distribution and reproduction in any medium or format, as long as you give appropriate credit to the original author(s) and the source, provide a link to the Creative Commons licence, and indicate if changes were made. The images or other third party material in this article are included in the article's Creative Commons licence, unless indicated otherwise in a credit line to the material. If material is not included in the article's Creative Commons licence and your intended use is not permitted by statutory regulation or exceeds the permitted use, you will need to obtain permission directly from the copyright holder. To view a copy of this licence, visit http:// creativecommons.org/licenses/by-nc/4.0/.

\section{REFERENCES}

1. World Health Organization. WHO Director-General's opening remarks at the media briefing on COVID-19-11 March 2020 [Internet]. [cited 2021 May 11]. Available from: https://www.who.int/ director-general/speeches/detail/who-directorgeneral-s-opening-remarks-at-the-media-briefingon-covid-19-11-march-2020

2. Ritchie H, Mathieu E, Rodés-Guirao L, Appel C, Giattino C, Ortiz-Ospina E, et al. Coronavirus Pandemic (COVID-19). Our World in Data [Internet]. 2020 [cited 2021 Sep 7]; Available from: https:// ourworldindata.org/coronavirus/country/italy

3. European Medicines Agency. EMA recommends first COVID-19 vaccine for authorisation in the EU [Internet]. European Medicines Agency. 2020 [cited 2021 May 6]. Available from: https://www.ema. europa.eu/en/news/ema-recommends-first-covid19-vaccine-authorisation-eu

4. US Food and Drug Administration. Pfizer-BioNTech COVID-19 Vaccine. FDA [Internet]. FDA; 2021 [cited 2021 May 6]; Available from: https://www. fda.gov/emergency-preparedness-and-response/ coronavirus-disease-2019-covid-19/pfizer-biontechcovid-19-vaccine

5. Huang C, Wang Y, Li X, Ren L, Zhao J, Hu Y, et al. Clinical features of patients infected with 2019 novel coronavirus in Wuhan, China. Lancet. 2020;395:497-506.

6. Siddiqi HK, Mehra MR. COVID-19 illness in native and immunosuppressed states: A clinical-therapeutic staging proposal. J Heart Lung Transplant. 2020;39:405-7.

7. European Centre for Disease Prevention and Control. COVID-19 vaccination and prioritisation strategies in the EU/EEA [Internet]. 2020 [cited 2021 May 11]. Available from: https://www.ecdc.europa. eu/en/publications-data/covid-19-vaccination-andprioritisation-strategies-eueea

8. COVID19 Vaccine Tracker. Vaccines [Internet]. [cited 2021 May 11]. Available from: https:// covid19.trackvaccines.org/vaccines/

9. Naqvi AAT, Fatima K, Mohammad T, Fatima U, Singh IK, Singh A, et al. Insights into SARS-CoV-2 genome, structure, evolution, pathogenesis and therapies: Structural genomics approach. Biochim Biophys Acta Mol Basis Dis. 2020;1866:165878.

10. Vagnoni C. Which SARS-CoV-2 variants reduce the effectiveness of vaccines? 2021 [cited 2021 Aug 4]; Available from: https://post.parliament.uk/whichsars-cov-2-variants-reduce-the-effectiveness-ofvaccines/

11. Jeyanathan M, Afkhami S, Smaill F, Miller MS, Lichty BD, Xing Z. Immunological considerations for COVID-19 vaccine strategies. Nature Reviews Immunology. Nature Publish Group. 2020;20: 615-32. 
12. Fajgenbaum DC, June CH. Cytokine storm. N Engl J Med Mass Med Soc. 2020;383:22-73.

13. Long Q-X, Tang X-J, Shi Q-L, Li Q, Deng H-J, Yuan J, et al. Clinical and immunological assessment of asymptomatic SARS-CoV-2 infections. Nature Medicine. Nature Publish Group. 2020;26:1200-4.

14. Hellerstein M. What are the roles of antibodies versus a durable, high quality $\mathrm{T}$-cell response in protective immunity against SARS-CoV-2? Vaccine X. 2020;6:100076.

15. Schwarzkopf S, Krawczyk A, Knop D, Klump H, Heinold A, Heinemann FM, et al. Cellular immunity in COVID-19 convalescents with PCR-confirmed infection but with undetectable SARS-CoV2-specific IgG. Emerg Infect Dis. 2021;27:122.

16. Ni L, Ye F, Cheng M-L, Feng Y, Deng Y-Q, Zhao H, et al. Detection of SARS-CoV-2-specific humoral and cellular immunity in COVID-19 convalescent individuals. Immunity. 2020;52:971-977.e3.

17. Grifoni A, Weiskopf D, Ramirez SI, Mateus J, Dan JM, Moderbacher CR, et al. Targets of $T$ cell responses to SARS-CoV-2 coronavirus in humans with COVID-19 disease and unexposed individuals. Cell. 2020;181:1489-1501.e15.

18. Lee DCP, Harker JAE, Tregoning JS, Atabani SF, Johansson C, Schwarze J, et al. CD25+ natural regulatory $\mathrm{T}$ cells are critical in limiting innate and adaptive immunity and resolving disease following respiratory syncytial virus infection. J Virol. 2010;84:8790-8.

19. Yu W, Geng S, Suo Y, Wei X, Cai Q, Wu B, et al. Critical role of regulatory $\mathrm{T}$ cells in the latency and stress-induced reactivation of HSV-1. Cell Rep. 2018;25:2379-89.e3

20. Anghelina D, Zhao J, Trandem K, Perlman S. Role of regulatory $\mathrm{T}$ cells in coronavirus-induced acute encephalitis. Virology. 2009;385:358-67.

21. Jung MK, Shin E-C. Regulatory T cells in hepatitis B and $C$ virus infections. Immune Netw. 2016;16: $330-6$.

22. Rahimzadeh M, Naderi N. Toward an understanding of regulatory T cells in COVID-19: A systematic review. J Med Virol. 2021;93:4167-81.

23. Jia R, Wang X, Liu P, Liang X, Ge Y, Tian H, et al. Mild cytokine elevation, moderate CD4+ $\mathrm{T}$ cell response and abundant antibody production in children with COVID-19. Virol Sin. 2020;35: 734-43.

24. De Biasi S, Meschiari M, Gibellini L, Bellinazzi C, Borella R, Fidanza L, et al. Marked T cell activation, senescence, exhaustion and skewing towards TH17 in patients with COVID-19 pneumonia. Nat Commun. 2020;11:3434.

25. Gao M, Liu Y, Guo M, Wang Q, Wang Y, Fan J, et al. Regulatory CD4+ and CD8 + T cells are negatively correlated with CD4+/CD8 + T cell ratios in patients acutely infected with SARS-CoV-2. J Leukoc Biol. 2021;109:91-7.

26. Rosenblum MD, Way SS, Abbas AK. Regulatory T cell memory. Nat Rev Immunol. 2016;16:90-101.

27. Persson R, Lee S, Yood MC, Wagner CM, Minton N, Niemcryk $S$, et al. Infections in patients diagnosed with multiple sclerosis: A multi-database study. Mult Scler Relat Disord. 2020;41:101982.

28. Wijnands JM, Kingwell E, Zhu F, Zhao Y, Fisk JD, Evans C, et al. Infection-related health care utilization among people with and without multiple sclerosis. Mult Scler. 2017;23:1506-16.

29. Montgomery S, Hillert J, Bahmanyar S. Hospital admission due to infections in multiple sclerosis patients. Eur J Neurol. 2013;20:1153-60.

30. Furer V, Rondaan C, Heijstek M, van Assen S, Bijl M, Agmon-Levin $\mathrm{N}$, et al. Incidence and prevalence of vaccine preventable infections in adult patients with autoimmune inflammatory rheumatic diseases (AIIRD): a systemic literature review informing the 2019 update of the EULAR recommendations for vaccination in adult patients with AIIRD. RMD Open. 2019;5: e001041.

31. Reder AT, Centonze D, Naylor ML, Nagpal A, Rajbhandari R, Altincatal A, et al. COVID-19 in patients with multiple sclerosis: associations with diseasemodifying therapies. CNS Drugs. 2021;35:317-30.

32. Chisari CG, Toscano S, D'Amico E, Lo Fermo S, Zanghì A, Arena S, et al. An update on the safety of treating relapsing-remitting multiple sclerosis. Expert Opin Drug Saf. 2019;18:925-48.

33. Chisari CG, Sgarlata E, Arena S, Toscano S, Luca M, Patti F. Rituximab for the treatment of multiple sclerosis: a review. J Neurol. 2021

34. Luna G, Alping P, Burman J, Fink K, Fogdell-Hahn $A$, Gunnarsson $M$, et al. Infection risks among patients with multiple sclerosis treated with fingolimod, natalizumab, rituximab, and injectable therapies. JAMA Neurol. 2020;77:184-91.

35. Wijnands JMA, Zhu F, Kingwell E, Fisk JD, Evans C, Marrie RA, et al. Disease-modifying drugs for multiple sclerosis and infection risk: a cohort study. J Neurol Neurosurg Psychiatry. 2018;89:1050-6. 
36. Sahraian MA, Azimi A, Navardi S, Ala S, Naser Moghadasi A. Evaluation of the rate of COVID-19 infection, hospitalization and death among Iranian patients with multiple sclerosis. Mult Scler Relat Disord. 2020;46:102472.

37. Evangelou N, Garjani A, dasNair R, Hunter R, TuiteDalton KA, Craig EM, et al. Self-diagnosed COVID19 in people with multiple sclerosis: a communitybased cohort of the UK MS Register. J Neurol Neurosurg Psychiatry. 2021;92:107-9.

38. Zabalza A, Cárdenas-Robledo S, Tagliani P, Arrambide G, Otero-Romero S, Carbonell-Mirabent P, et al. COVID-19 in multiple sclerosis patients: susceptibility, severity risk factors and serological response. Eur J Neurol. 2020. https://doi.org/10. 1111/ene.14690.

39. Emmi G, Bettiol A, Mattioli I, Silvestri E, Di Scala G, Urban ML, et al. SARS-CoV-2 infection among patients with systemic autoimmune diseases. Autoimmun Rev. 2020;19:102575.

40. Louapre C, Collongues N, Stankoff B, Giannesini C, Papeix C, Bensa C, et al. Clinical Characteristics and outcomes in patients with coronavirus disease 2019 and multiple sclerosis. JAMA Neurol. 2020;77: 1079-88.

41. Sormani MP, Salvetti M, Labauge P, Schiavetti I, Zephir H, Carmisciano L, et al. DMTs and Covid-19 severity in MS: a pooled analysis from Italy and France. Ann Clin Transl Neurol. 2021;8:1738-44.

42. Bastard P, Rosen LB, Zhang Q, Michailidis E, Hoffmann $\mathrm{H}-\mathrm{H}$, Zhang $\mathrm{Y}$, et al. Autoantibodies against type I IFNs in patients with life-threatening COVID19. Science [Internet]. American Association for the Advancement of Science; 2020 [cited 2021 Aug 4];370. Available from: https://science.sciencemag. org/content/370/6515/eabd4585

43. Zhang Q, Bastard P, Liu Z, Le Pen J, Moncada-Velez $M$, Chen $J$, et al. Inborn errors of type I IFN immunity in patients with life-threatening COVID19. Science. 2020;370: eabd4570.

44. Berger JR, Brandstadter R, Bar-Or A. COVID-19 and MS disease-modifying therapies. Neurology - Neuroimmunology Neuroinflammation [Internet]. Wolters Kluwer Health, Inc. on behalf of the American Academy of Neurology; 2020 [cited 2021 Apr 22];7. Available from: https://nn.neurology. org/content/7/4/e761

45. Garjani A, Middleton RM, Hunter R, Tuite-Dalton KA, Coles A, Dobson R, et al. COVID-19 is associated with multiple sclerosis exacerbations that are prevented by disease modifying therapies. medRxiv. Cold Spring Harbor Laboratory Press; 2021; 2021. 03.08.21253141.
46. Portaccio E, Fonderico $\mathrm{M}$, Hemmer B, Derfuss $\mathrm{T}$, Stankoff B, Selmaj K, et al. Impact of COVID-19 on multiple sclerosis care and management: Results from the European Committee for Treatment and Research in Multiple Sclerosis survey. Mult Scler. $2021 ; 13524585211005340$.

47. Mateen FJ, Rezaei S, Alakel N, Gazdag B, Kumar AR, Vogel A. Impact of COVID-19 on U.S. and Canadian neurologists' therapeutic approach to multiple sclerosis: a survey of knowledge, attitudes, and practices. J Neurol. 2020;267:3467-75.

48. Morrison EH, Michtich K, Hersh CM. How the COVID-19 Pandemic has changed multiple sclerosis clinical practice: Results of a nationwide provider survey. Mult Scler Relat Disord. 2021;51:102913.

49. Loonstra FC, Hoitsma E, van Kempen ZL, Killestein J, Mostert JP. COVID-19 in multiple sclerosis: The Dutch experience. Mult Scler. 2020;26:1256-60.

50. Sormani MP, De Rossi N, Schiavetti I, Carmisciano L, Cordioli C, Moiola L, et al. Disease-modifying therapies and coronavirus disease 2019 severity in multiple sclerosis. Ann Neurol. 2021;89:780-9.

51. Wang N, Zhan Y, Zhu L, Hou Z, Liu F, Song P, et al. Retrospective multicenter cohort study shows early interferon therapy is associated with favorable clinical responses in COVID-19 patients. Cell Host Microbe. 2020;28:455-464.e2.

52. Sormani MP. An Italian programme for COVID-19 infection in multiple sclerosis. Lancet Neurol Elsevier. 2020;19:481-2.

53. Salter A, Fox RJ, Newsome SD, Halper J, Li DKB, Kanellis $\mathrm{P}$, et al. Outcomes and risk factors associated with SARS-CoV-2 infection in a North American registry of patients with multiple sclerosis. JAMA Neurol. 2021;78:699-708.

54. Simpson-Yap S, Brouwer ED, Kalincik T, Rijke N, Hillert J, Walton C, et al. Associations of DMT therapies with COVID-19 severity in multiple sclerosis. medRxiv. Cold Spring Harbor Laboratory Press; 2021;2021.02.08.21251316.

55. Hughes R, Whitley L, Fitovski K, Schneble H-M, Muros E, Sauter A, et al. COVID-19 in ocrelizumabtreated people with multiple sclerosis. Mult Scler Relat Disord. 2021;49:102725.

56. Fernández-Díaz E, Gracia-Gil J, García-García JG, Palao M, Romero-Sánchez CM, Segura T. COVID-19 and multiple sclerosis: A description of two cases on alemtuzumab. Mult Scler Relat Disord. 2020;45: 102402.

57. Centonze D, Rocca MA, Gasperini C, Kappos L, Hartung H-P, Magyari M, et al. Disease-modifying 
therapies and SARS-CoV-2 vaccination in multiple sclerosis: an expert consensus. J Neurol. 2021

58. Thakolwiboon S, Zhao-Fleming H, Pan J, Scott JK, Shoji E, Sohn G, et al. Disease-modifying therapies during the COVID-19 Outbreak: a narrative review of international and national recommendations. Int J MS Care. 2020;22:151-7.

59. Società Italiana di Neurologia. Raccomandazioni globali sul COVID-19 per le persone con SM [Internet]. [cited 2021 May 3]. Available from: http:// www.neuro.it/web/procedure/contenuto.cfm?List= WsPageNameCaller,WsIdEvento, $\mathrm{W}$

sIdRisposta,WsRelease\& $\quad$ c1=\%2Fweb\%2Feventi\% 2FNEURO $\% 2$ Fcovid\%2D19\%2Ecfm\%3FList $\%$ 3DWsStartRow\%26c1\%3D1\&c2=NWSNEURO\&c3= $189 \& \mathrm{c} 4=1$

60. MS International Federation. The coronavirus and MS - updated global advice [Internet]. MS International Federation. 2020 [cited 2021 Apr 27]. Available from: https://www.msif.org/news/2020/02/10/ the-coronavirus-and-ms-what-you-need-to-know/

61. European Multiple Sclerosis Platform. Updated global COVID-19 advice for people with MS [Internet]. EMSP | European Multiple Sclerosis Platform. [cited 2021 May 3]. Available from: http://www.emsp.org/ news-messages/coronavirus-disease-covid-19-andmultiple-sclerosis/

62. Sellner J, Rommer PS. Multiple sclerosis and SARSCoV-2 vaccination: considerations for immune-depleting therapies. Vaccines (Basel). 2021;2:99.

63. Giovannoni G, Hawkes C, Lechner-Scott J, Levy M, Waubant E, Gold J. The COVID-19 pandemic and the use of MS disease-modifying therapies. Mult Scler Relat Disord. 2020;39:102073.

64. Multiple Sclerosis Society UK. COVID-19 coronavirus and MS | Multiple Sclerosis Society UK [Internet]. [cited 2021 May 3]. Available from: https:// www.mssociety.org.uk/about-ms/treatments-andtherapies/disease-modifying-therapies/covid-19coronavirus-and-ms

65. Burt RK, Balabanov R, Burman J, Sharrack B, Snowden JA, Oliveira MC, et al. Effect of nonmyeloablative hematopoietic stem cell transplantation vs continued disease-modifying therapy on disease progression in patients with relapsingremitting multiple sclerosis: a randomized clinical trial. JAMA. 2019;321:165-74.

66. Ljungman P, Mikulska M, de la Camara R, Basak GW, Chabannon C, Corbacioglu S, et al. The challenge of COVID-19 and hematopoietic cell transplantation; EBMT recommendations for management of hematopoietic cell transplant recipients, their donors, and patients undergoing
CAR T-cell therapy. Bone Marrow Transplant. 2020;55:2071-6.

67. Greco R, Alexander T, Burman J, Del Papa N, de Vries-Bouwstra J, Farge D, et al. Hematopoietic stem cell transplantation for autoimmune diseases in the time of COVID-19: EBMT guidelines and recommendations. Bone Marrow Transplant. 2021;56: 1493-508.

68. Sharma A, Bhatt NS, Martin AS, Abid MB, Bloomquist J, Chemaly RF, et al. Clinical characteristics and outcomes of COVID-19 in haematopoietic stem-cell transplantation recipients: an observational cohort study. Lancet Haematol Elsevier. 2021;8:e185-93.

69. Schwid SR, Decker MD, Lopez-Bresnahan M. RebifInfluenza Vaccine Study Investigators. Immune response to influenza vaccine is maintained in patients with multiple sclerosis receiving interferon beta-1a. Neurology. 2005;65:1964-6.

70. Metze C, Winkelmann A, Loebermann M, Hecker M, Schweiger B, Reisinger EC, et al. Immunogenicity and predictors of response to a single dose trivalent seasonal influenza vaccine in multiple sclerosis patients receiving disease-modifying therapies. CNS Neurosci Ther. 2019;25:245-54.

71. Olberg HK, Cox RJ, Nostbakken JK, Aarseth JH, Vedeler CA, Myhr K-M. Immunotherapies influence the influenza vaccination response in multiple sclerosis patients: an explorative study. Mult Scler. 2014;20:1074-80.

72. Olberg HK, Eide GE, Cox RJ, Jul-Larsen $\AA$, Lartey SL, Vedeler CA, et al. Antibody response to seasonal influenza vaccination in patients with multiple sclerosis receiving immunomodulatory therapy. Eur J Neurol. 2018;25:527-34.

73. Bar-Or A, Freedman MS, Kremenchutzky M, Menguy-Vacheron F, Bauer D, Jodl S, et al. Teriflunomide effect on immune response to influenza vaccine in patients with multiple sclerosis. Neurology. 2013;81:552-8.

74. von Hehn C, Howard J, Liu S, Meka V, Pultz J, Mehta D, et al. Immune response to vaccines is maintained in patients treated with dimethyl fumarate. Neurol Neuroimmunol Neuroinflamm. 2018;5: e409.

75. Epstein DJ, Dunn J, Deresinski S. Infectious complications of multiple sclerosis therapies: implications for screening, prophylaxis, and management. Open Forum Infect Dis. 2018;5:ofy174.

76. Kappos L, Mehling M, Arroyo R, Izquierdo G, Selmaj $\mathrm{K}$, Curovic-Perisic V, et al. Randomized trial of 
vaccination in fingolimod-treated patients with multiple sclerosis. Neurology. 2015;84:872-9.

77. Wu GF, Boschert U, Hayward B, Lebson LA, Cross $\mathrm{AH}$. Evaluating the impact of cladribine tablets on the development of antibody titers: interim results from the CLOCK-MS influenza vaccine substudy. ACTRIMS. 2021;2021:9.

78. Roy S, Boschert U. Analysis of influenza and varicella zoster virus vaccine antibody titers in patients with relapsing multiple sclerosis treated with cladribine tablets. Magnetic Resonance Imag. 2021;10:25-7.

79. Vågberg M, Kumlin U, Svenningsson A. Humoral immune response to influenza vaccine in natalizumab-treated MS patients. Neurol Res. 2012;34: 730-3.

80. Kaufman M, Pardo G, Rossman H, Sweetser MT, Forrestal F, Duda P. Natalizumab treatment shows no clinically meaningful effects on immunization responses in patients with relapsing-remitting multiple sclerosis. J Neurol Sci. 2014;341:22-7.

81. European Medicines Agency. Lemtrada - Summary of Product Characteristics [Internet]. European Medicines Agency. 2018 [cited 2021 Apr 27]. Available from: https://www.ema.europa.eu/en/ medicines/human/EPAR/lemtrada

82. McCarthy CL, Tuohy O, Compston DAS, Kumararatne DS, Coles AJ, Jones JL. Immune competence after alemtuzumab treatment of multiple sclerosis. Neurology. 2013;81:872-6.

83. Bar-Or A, Calkwood JC, Chognot C, Evershed J, Fox EJ, Herman A, et al. Effect of ocrelizumab on vaccine responses in patients with multiple sclerosis: The VELOCE study. Neurology. 2020;95:e19992008.

84. Westra J, van Assen S, Wilting KR, Land J, Horst G, de Haan A, et al. Rituximab impairs immunoglobulin (Ig)M and IgG (subclass) responses after influenza vaccination in rheumatoid arthritis patients. Clin Exp Immunol. 2014;178:40-7.

85. Riva A, Barcella V, Benatti SV, Capobianco M, Capra $\mathrm{R}$, Cinque $\mathrm{P}$, et al. Vaccinations in patients with multiple sclerosis: A Delphi consensus statement. Mult Scler. 2021;27:347-59.

86. Ljungman $\mathrm{P}$, Engelhard D, de la Cámara R, Einsele $\mathrm{H}$, Locasciulli A, Martino R, et al. Vaccination of stem cell transplant recipients: recommendations of the Infectious Diseases Working Party of the EBMT. Bone Marrow Transplant. 2005;35:737-46.
87. Johnston BL, Conly JM. Immunization for bone marrow transplant recipients. Can J Infect Dis. 2002;13:353-7.

88. Chong PP, Avery RK. A comprehensive review of immunization practices in solid organ transplant and hematopoietic stem cell transplant recipients. Clin Therapeut Elsevier. 2017;39:1581-98.

89. Ljungman $\mathrm{P}$, Cordonnier $\mathrm{C}$, de Bock R, Einsele $\mathrm{H}$, Engelhard D, Grundy J, et al. Immunisations after bone marrow transplantation: results of a European survey and recommendations from the infectious diseases working party of the European Group for Blood and Marrow Transplantation. Bone Marrow Transplant. 1995;15:455-60.

90. Buchholz UJ, Bukreyev A, Yang L, Lamirande EW, Murphy BR, Subbarao K, et al. Contributions of the structural proteins of severe acute respiratory syndrome coronavirus to protective immunity. Proc Natl Acad Sci U S A. 2004;101:9804-9.

91. European Medicines Agency. Comirnaty [Internet]. European Medicines Agency. 2020 [cited 2021 May 6]. Available from: https://www.ema.europa.eu/en/ medicines/human/EPAR/comirnaty

92. European Medicines Agency. EMA recommends COVID-19 Vaccine Moderna for authorisation in the EU [Internet]. European Medicines Agency. 2021 [cited 2021 May 6]. Available from: https:// www.ema.europa.eu/en/news/ema-recommendscovid-19-vaccine-moderna-authorisation-eu

93. US Food and Drug Administration. Moderna COVID-19 Vaccine. FDA [Internet]. FDA; 2021 [cited 2021 May 6]; Available from: https://www. fda.gov/emergency-preparedness-and-response/ coronavirus-disease-2019-covid-19/moderna-covid19-vaccine

94. Polack FP, Thomas SJ, Kitchin N, Absalon J, Gurtman A, Lockhart S, et al. Safety and Efficacy of the BNT162b2 mRNA Covid-19 Vaccine. N England J Med Massachusetts Med Soc. 2020;383:2603-15.

95. Baden LR, El Sahly HM, Essink B, Kotloff K, Frey S, Novak R, et al. Efficacy and Safety of the mRNA1273 SARS-CoV-2 Vaccine. N England J Med Massachusetts Med Soc. 2021;384:403-16.

96. European Medicines Agency. EMA recommends COVID-19 Vaccine Janssen for authorisation in the EU [Internet]. European Medicines Agency. 2021 [cited 2021 May 6]. Available from: https://www. ema.europa.eu/en/news/ema-recommends-covid19-vaccine-janssen-authorisation-eu

97. European Medicines Agency. EMA recommends COVID-19 Vaccine AstraZeneca for authorisation in the EU [Internet]. European Medicines Agency. 
2021 [cited 2021 May 6]. Available from: https:// www.ema.europa.eu/en/news/ema-recommendscovid-19-vaccine-astrazeneca-authorisation-eu

98. US Food and Drug Administration. Janssen COVID19 Vaccine. FDA [Internet]. FDA; 2021 [cited 2021 Aug 11]; Available from: https://www.fda.gov/ emergency-preparedness-and-response/ coronavirus-disease-2019-covid-19/janssen-covid19-vaccine

99. Dong Y, Dai T, Wei Y, Zhang L, Zheng M, Zhou F. A systematic review of SARS-CoV-2 vaccine candidates. Signal Transduct Target Ther. 2020;5:237.

100. Voysey M, Clemens SAC, Madhi SA, Weckx LY, Folegatti PM, Aley PK, et al. Safety and efficacy of the ChAdOx1 nCoV-19 vaccine (AZD1222) against SARS-CoV-2: an interim analysis of four randomised controlled trials in Brazil, South Africa, and the UK. The Lancet Elsevier. 2021;397:99-111.

101. Sadoff J, Gray G, Vandebosch A, Cárdenas V, Shukarev G, Grinsztejn B, et al. Safety and efficacy of single-dose Ad26.COV2.S Vaccine against Covid-19. N England J Med Massachusetts Med Soc 2021;0: null.

102. US Food and Drug Administration. COVID-19 Vaccines. FDA [Internet]. FDA; 2021 [cited 2021 Apr 26]; Available from: https://www.fda.gov/ emergency-preparedness-and-response/

coronavirus-disease-2019-covid-19/covid-19vaccines

103. European Medicines Agency. COVID-19 vaccines [Internet]. European Medicines Agency. 2021 [cited 2021 Apr 26]. Available from: https://www.ema. europa.eu/en/human-regulatory/overview/publichealth-threats/coronavirus-disease-covid-19/ treatments-vaccines/covid-19-vaccines

104. Achiron A, Dolev M, Menascu S, Zohar D-N, DreyerAlster S, Miron S, et al. COVID-19 vaccination in patients with multiple sclerosis: What we have learnt by February 2021. Mult Scler. 2021;27: 864-70.

105. Di Filippo M, Cordioli C, Malucchi S, Annovazzi P, Cavalla P, Torri Clerici V, et al. mRNA COVID-19 vaccines do not increase the short-term risk of clinical relapses in multiple sclerosis. J Neurol Neurosurg Psychiatry. 2021;327200.

106. Korsukewitz C, Reddel SW, Bar-Or A, Wiendl H. Neurological immunotherapy in the era of COVID19 - looking for consensus in the literature. Nat Rev Neurol. 2020;16:493-505.

107. Baker D, Roberts CAK, Pryce G, Kang AS, Marta M, Reyes $\mathrm{S}$, et al. COVID-19 vaccine-readiness for anti-
CD20-depleting therapy in autoimmune diseases. Clin Exp Immunol. 2020;202:149-61.

108. European Medicines Agency. Ocrevus - Summary of Product Characteristics [Internet]. European Medicines Agency. 2018 [cited 2021 May 4]. Available from: https://www.ema.europa.eu/en/ medicines/human/EPAR/ocrevus

109. Marcinnò A, Marnetto F, Valentino $\mathrm{P}$, Martire S, Balbo A, Drago A, et al. Rituximab-induced hypogammaglobulinemia in patients with neuromyelitis optica spectrum disorders. Neurol Neuroimmunol Neuroinflamm. 2018;5: e498.

110. Cho A, Bradley B, Kauffman R, Priyamvada L, Kovalenkov Y, Feldman R, et al. Robust memory responses against influenza vaccination in pemphigus patients previously treated with rituximab. JCI Insight [Internet]. [cited 2021 May 4];2. Available from: https://www.ncbi.nlm.nih.gov/pmc/ articles/PMC5470882/

111. Sormani MP, Schiavetti I, Landi D, Carmisciano L, De Rossi N, Cordioli C, et al. SARS-CoV-2 serology after COVID-19 in multiple sclerosis: An international cohort study. Mult Scler. SAGE Publications Ltd STM; 2021;13524585211035318.

112. Conte WL. Attenuation of antibody response to SARS-CoV-2 in a patient on ocrelizumab with hypogammaglobulinemia. Mult Scler Relat Disord. 2020;44:102315.

113. Conte WL. Attenuation of antibody response to SARS-CoV-2 infection in patients with multiple sclerosis on ocrelizumab: A case-control study. Mult Scler Relat Disord. 2021;52:103014.

114. Gallo A, Capuano R, Donnarumma G, Bisecco A, Grimaldi E, Conte $\mathrm{M}$, et al. Preliminary evidence of blunted humoral response to SARS-CoV-2 mRNA vaccine in multiple sclerosis patients treated with ocrelizumab. Neurol Sci. 2021;42:3523-6.

115. Gadani SP, Reyes-Mantilla M, Jank L, Harris S, Douglas M, Smith MD, et al. Discordant humoral and $\mathrm{T}$ cell immune responses to SARS-CoV-2 vaccination in people with multiple sclerosis on antiCD20 therapy. medRxiv. 2021;2021.08.23. 21262472.

116. Iannetta M, Landi D, Cola G, Malagnino V, Teti E, Fraboni D, et al. T-cell responses to SARS-CoV-2 in multiple sclerosis patients treated with ocrelizumab healed from COVID-19 with absent or low antispike antibody titers. Mult Scler Relat Disord. 2021;55:103157.

117. Zheng C, Kar I, Chen CK, Sau C, Woodson S, Serra A, et al. Multiple Sclerosis Disease-Modifying Therapy and the COVID-19 Pandemic: Implications on 
the Risk of Infection and Future Vaccination. CNS Drugs. 2020;1:18.

118. Bollo L, Guerra T, Bavaro DF, Monno L, Saracino A, Angarano $\mathrm{G}$, et al. Seroconversion and indolent course of COVID-19 in patients with multiple sclerosis treated with fingolimod and teriflunomide. J Neurol Sci. 2020;416:117011.

119. Ciotti JR, Valtcheva MV, Cross AH. Effects of MS disease-modifying therapies on responses to vaccinations: A review. Multiple Sclerosis and Related Disorders. Elsevier; 2020;45:102439

120. Capuano R, Donnarumma G, Bisecco A, Grimaldi E, Conte M, d'Ambrosio A, et al. Humoral response to SARS-CoV-2 mRNA vaccine in patients with multiple sclerosis treated with natalizumab. Ther Adv Neurol Disord. 2021;14:17562864211038112.

121. Achiron A, Mandel M, Dreyer-Alster S, Harari G, Magalashvili D, Sonis P, et al. Humoral immune response to COVID-19 mRNA vaccine in patients with multiple sclerosis treated with high-efficacy disease-modifying therapies. Ther Adv Neurol Disord. SAGE Publications Ltd STM; 2021;14: 17562864211012836.

122. McDade TW, Demonbreun AR, Sancilio A, Mustanski B, D'Aquila RT, McNally EM. Durability of antibody response to vaccination and surrogate neutralization of emerging variants based on SARSCoV-2 exposure history. Sci Rep. 2021;11:17325.

123. Thomas SJ, Moreira ED, Kitchin N, Absalon J, Gurtman A, Lockhart S, et al. Six Month Safety and Efficacy of the BNT162b2 mRNA COVID-19 Vaccine [Internet]. 2021 Jul p. 2021.07.28.21261159. Available from: https://www.medrxiv.org/content/ https://doi.org/10.1101/2021.07.28.21261159v1

124. Pegu A, O'Connell S, Schmidt SD, O'Dell S, Talana CA, Lai L, et al. Durability of mRNA-1273 vaccine-induced antibodies against SARS-CoV-2 variants. Science [Internet]. American Association for the Advancement of Science; 2021 [cited 2021 Sep 8]; Available from: https://www.science.org/doi/ abs/https://doi.org/10.1126/science.abj4176

125. US Food and Drug Administration. Coronavirus (COVID-19) Update: FDA Authorizes Additional Vaccine Dose for Certain Immunocompromised Individuals [Internet]. FDA. FDA; 2021 [cited 2021 Sep 8]. Available from: https://www.fda.gov/newsevents/press-announcements/coronavirus-covid19-update-fda-authorizes-additional-vaccine-dosecertain-immunocompromised

126. Centers for Disease Control and Prevention. COVID-19 Booster Vaccine [Internet]. 2021 [cited 2021 Sep 8]. Available from: https://www.cdc.gov/ coronavirus/2019-ncov/vaccines/booster-shot.html
127. Public Health England. JCVI issues advice on third dose vaccination for severely immunosuppressed [Internet]. GOV.UK. [cited 2021 Sep 8]. Available from: https://www.gov.uk/government/news/jcviissues-advice-on-third-dose-vaccination-forseverely-immunosuppressed

128. Furlong A, Deutsch J. A country-by-country guide to coronavirus vaccine booster plans [Internet]. POLITICO. 2021 [cited 2021 Sep 8]. Available from: https://www.politico.eu/article/vaccine-boostercoronavirus-covid-19-europe-delta-varian-who/

129. Costa Frossard-França L, García-Domínguez JM, Moreno-Torres I, Fortún J, Villar LM. Meca-Lallana $\mathrm{V}$ [Vaccination against SARS-CoV-2 in patients with multiple sclerosis]. Rev Neurol. 2021;72:250-60.

130. Otero-Romero S, Ascherio A, Lebrun-Frénay C. Vaccinations in multiple sclerosis patients receiving disease-modifying drugs. Curr Opin Neurol. 2021;34(3):322-8.

131. Ferretti F, Cannatelli R, Benucci M, Carmagnola S, Clementi E, Danelli P, et al. How to Manage COVID-19 Vaccination in Immune-Mediated Inflammatory Diseases: An Expert Opinion by IMIDs Study Group. Front Immunol [Internet]. Frontiers; 2021 [cited 2021 May 5];12. Available from: https://www.frontiersin.org/articles/https:// doi.org/10.3389/fimmu.2021.656362/full

132. MS Australia. COVID-19 vaccination guidance for people with MS [Internet]. 2021 [cited 2021 May 5]. Available from: https://www.msaustralia.org.au/ about-ms/covid-19-and-ms/covid-19-vaccinationguidance-people-ms

133. MS New Zealand. [Updated] COVID-19 - Advice for Patients [Internet]. Multiple Sclerosis Society of NZ. 2020 [cited 2021 Jun 15]. Available from: https:// www.msnz.org.nz/covid-19-advice-for-patients/

134. MS Ireland. COVID-19 and MS [Internet]. 2020 [cited 2021 Jun 15]. Available from: https://www. ms-society.ie/covid-19-and-ms

135. Association of British Neurologists. Updated ABN Guidance on DMTs for MS and COVID19 [Internet]. [cited 2021 Jun 15]. Available from: https://www. theabn.org/news/537859/Updated-ABN-Guidanceon-DMTs-for-MS-and-COVID19.htm

136. European Academy of Neurology. Immunotherapy for patients with neuroimmunological disorders during the COVID-19 pandemic [Internet]. eanpages. 2020 [cited 2021 Jun 15]. Available from: https://www.eanpages.org/2020/04/01/ immunotherapy-for-patients-withneuroimmunological-disorders-during-the-covid19-pandemic/ 
137. Robertson S. Real-world evidence SARS-CoV-2 mRNA vaccines work and help prevent worst outcomes [Internet]. News-Medical.net. 2021 [cited 2021 Aug 11]. Available from: https://www.newsmedical.net/news/20210712/Real-world-evidenceSARS-CoV-2-mRNA-vaccines-work-and-helpprevent-worst-outcomes.aspx

138. Lopez Bernal J, Andrews N, Gower C, Gallagher E, Simmons R, Thelwall S, et al. Effectiveness of Covid19 Vaccines against the B.1.617.2 (Delta) Variant. N Engl J Med Mass Med Soc 2021;0:null.

139. Puranik A, Lenehan PJ, Silvert E, Niesen MJM, Corchado-Garcia J, O'Horo JC, et al. Comparison of two highly-effective mRNA vaccines for COVID-19 during periods of Alpha and Delta variant prevalence [Internet]. 2021 Aug p. 2021.08.06.21261707. Available from: https://www.medrxiv.org/content/ https://doi.org/10.1101/2021.08.06.21261707v1

140. Public Health England. Vaccines highly effective against hospitalisation from Delta variant [Internet]. GOV.UK. [cited 2021 Aug 11]. Available from: https://www.gov.uk/government/news/vaccineshighly-effective-against-hospitalisation-from-deltavariant

141. US Food and Drug Administration. Coronavirus (COVID-19) Update: June 25, 2021 [Internet]. FDA. FDA; 2021 [cited 2021 Aug 11]. Available from: https://www.fda.gov/news-events/pressannouncements/coronavirus-covid-19-updatejune-25-2021

142. Kemp A. AZD1222 US Phase III primary analysis confirms safety and efficacy [Internet]. [cited 2021 Aug 11]. Available from: https://www.astrazeneca. $\mathrm{com} / \mathrm{media}$-centre/press-releases/2021/azd1222-usphase-iii-primary-analysis-confirms-safety-andefficacy.html

143. Wall EC, Wu M, Harvey R, Kelly G, Warchal S, Sawyer C, et al. AZD1222-induced neutralising antibody activity against SARS-CoV-2 Delta VOC. The Lancet Elsevier. 2021;398:207-9.

144. European Medicines Agency. AstraZeneca's COVID19 vaccine: EMA finds possible link to very rare cases of unusual blood clots with low platelets
[Internet]. European Medicines Agency. 2021 [cited 2021 Aug 11]. Available from: https://www.ema. europa.eu/en/news/astrazenecas-covid-19-vaccineema-finds-possible-link-very-rare-cases-unusualblood-clots-low-blood

145. Johnson\&Johnson. Johnson \& Johnson Single-Shot COVID-19 Vaccine Phase 3 Data Published in New England Journal of Medicine | Johnson \& Johnson [Internet]. [cited 2021 Aug 11]. Available from: https://www.jnj.com/johnson-johnson-single-shotcovid-19-vaccine-phase-3-data-published-in-newengland-journal-of-medicine

146. Johnson\&Johnson. Positive New Data for Johnson \& Johnson Single-Shot COVID-19 Vaccine on Activity Against Delta Variant and Long-lasting Durability of Response | Johnson \& Johnson [Internet]. Content Lab U.S. [cited 2021 Aug 11]. Available from: https://www.jnj.com/positive-newdata-for-johnson-johnson-single-shot-covid-19vaccine-on-activity-against-delta-variant-and-longlasting-durability-of-response

147. US Food and Drug Administration. Vaccines and Related Biological Products Advisory Committee February 26, 2021 Meeting Announcement - 02/26/ 2021 - 02/26/2021 [Internet]. FDA. 2021 [cited 2021 Aug 11]. Available from: https://www.fda.gov/ advisory-committees/advisory-committee-calendar/ vaccines-and-related-biological-products-advisorycommittee-february-26-2021-meetingannouncement

148. World Health Organization. Statement of the COVID-19 subcommittee of the WHO Global Advisory Committee on Vaccine Safety (GACVS) on safety signals related to the Johnson \& Johnson/ Janssen COVID-19 vaccine [Internet]. [cited 2021 Aug 11]. Available from: https://www.who.int/ news/item/19-05-2021-statement-gacvs-safetyjohnson-johnson-janssen-covid-19-vaccine

149. US Food and Drug Administration. Coronavirus (COVID-19) Update: July 13, 2021 [Internet]. FDA. FDA; 2021 [cited 2021 Aug 11]. Available from: https://www.fda.gov/news-events/pressannouncements/coronavirus-covid-19-update-july$13-2021$ 